This item was submitted to Loughborough's Research Repository by the author.

Items in Figshare are protected by copyright, with all rights reserved, unless otherwise indicated.

\title{
Critical wetting concentrations of trisiloxane surfactants
}

PLEASE CITE THE PUBLISHED VERSION

PUBLISHER

(C) Elsevier

VERSION

AM (Accepted Manuscript)

LICENCE

CC BY-NC-ND 4.0

\section{REPOSITORY RECORD}

Ivanova, Natalia A., Victor Starov, Ramon Rubio, Hernan Ritacco, Nidal Hilal, and Daniel Johnson. 2010. "Critical Wetting Concentrations of Trisiloxane Surfactants". figshare. https://hdl.handle.net/2134/5838. 
This item was submitted to Loughborough's Institutional Repository (https://dspace.lboro.ac.uk/) by the author and is made available under the following Creative Commons Licence conditions.

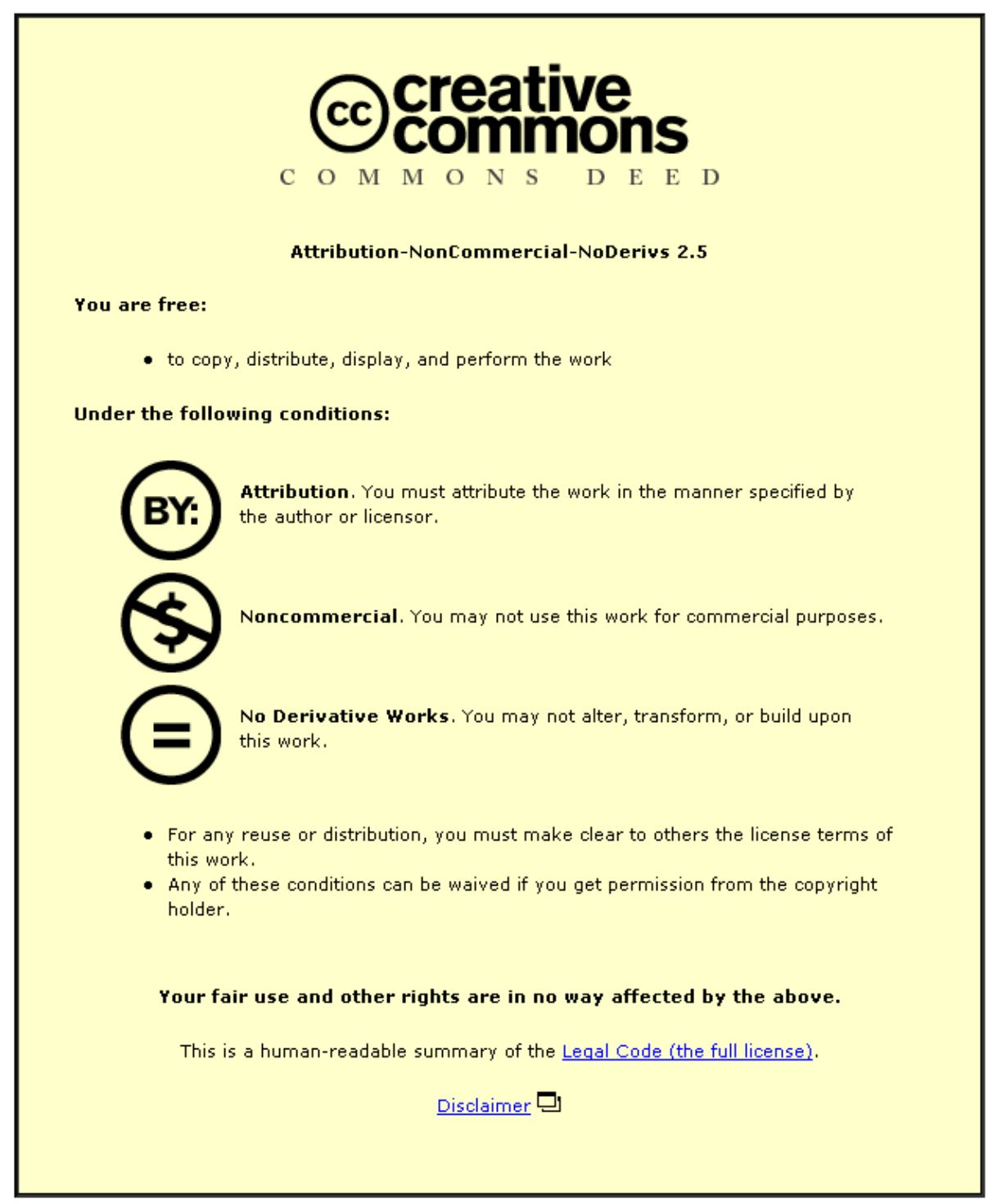

For the full text of this licence, please go to: http://creativecommons.org/licenses/by-nc-nd/2.5/ 


\title{
Critical wetting concentrations of trisiloxane surfactants
}

Natalia Ivanova ${ }^{1}$, Victor Starov $^{1 *}$, Ramon Rubio ${ }^{2}$, Hernán Ritacco $^{2}$, Nidal Hilal ${ }^{3}$, Daniel Johnson $^{3}$

${ }^{1}$ Department of Chemical Engineering, Loughborough University, Loughborough, LE11 3TU, UK

${ }^{2}$ Department of Quimica Fisica I, Faculty Quimica, Universidad Complutense, 28040Madrid, Spain

${ }^{3}$ Centre for Clean Water Technologies, Faculty of Engineering, University of Nottingham, University Park, Nottingham, NG7 2RD, UK

*Corresponding author V.M.Starov@1boro.ac.uk

\begin{abstract}
Trisiloxane surfactants also known as "superspreaders" are characterized by a critical wetting concentration (CWC) which has been determined by Svitova et al (Langmuir. 1998. 14, 5023 5031). CWC is a concentration above which a transition from partial wetting to complete wetting occurs at spreading over moderately hydrophobic surfaces, hence, the CWC is associated with the beginning of the superspreading. The latter shows that the knowledge of the CWCs is important for many wetting/spreading applications. We suggest a new method, which allows determining CWCs for a range of trisiloxanes using wetting behaviour of aqueous trisiloxane solutions on highly hydrophobic smooth Teflon AF coated silicon wafers. Using the new method the CWCs for trisiloxane surfactants, $\mathrm{T}_{\mathrm{n}}$ with a wide range in the number $(n=4-9)$ of ethylene oxide units have been measured. The critical aggregation concentration (CAC) for trisiloxane surfactants has been measured using the surface tension methods. Additionally, spreading kinetics of all trisiloxane surfactants studied over moderately hydrophobic substrates has been investigated. It has been found that for all trisiloxanes studied the CWCs are several times higher than their corresponding CAC values. The CWCs for $\mathrm{T}_{6}$ and $\mathrm{T}_{8}$ trisiloxanes obtained according to our approach are in agreement
\end{abstract}


with those measured by Svitova et al. (Langmuir. 1998. 14, 5023-5031) for the case of complete wetting. It has been verified that indeed at CWCs estimated according to our approach trisiloxane surfactant solutions demonstrate superspreading behaviour on moderately hydrophobic surfaces with the exception of trisiloxane $\mathrm{T}_{4}$, which still shows only partial wetting. Thus, the CWC does not depend on the degree of hydrophobicity of substrates and could be considered as a distinct property of surfactants that characterize the highest limit of their spreading capability.

Key words: trisiloxane, spreading, critical wetting concentration

\section{Introduction}

In a number of wetting processes such as painting, coating, and herbicide delivery applications an efficient wetting of water mixtures on solids is required. A simplest solution to that problem is to reduce the surface tension of both the liquid-vapor and liquid-solid interfaces of the water droplets through the addition of surfactants. However, in the case of hydrophobic surfaces not all of the surfactants are able to provide effective wetting. In the early 1990s trisiloxane surfactants (silicon-based surfactants) have been recognized possessing an unusual ability to induce a fast spreading of the water mixtures over low energy surfaces such as Parafilm and polyethylene. This phenomenon was referred to as “superspreading" [1-5]. Trisiloxane surfactant molecules in aqueous solutions spontaneously form dispersions of bilayer aggregates as the concentration of monomers exceeds a certain value, which is referred to as critical aggregation concentration (CAC). Although the airliquid surface tension of water trisiloxane solutions at concentrations above those at which the CAC is reached are at a relatively low value $\sim 20 \mathrm{mN} / \mathrm{m}$, it is not the lowest surface tension of water solution, which could be obtained by adding surfactants [6]. However, in spite of that fact, the trisiloxane surfactants can promote rapid spreading of water droplets over hydrophobic surfaces and even wet them completely. It has been revealed in [7] an existence 
of some critical wetting concentration (CWC) for trisiloxane surfactants above which the transition from partial wetting to complete wetting takes place on some moderately hydrophobic surfaces, leading to "superspreading". It means that the CWC is associated with the beginning the superspreading process. The CWC for trisiloxanes with 6,8 and 12 ethylene oxide units is substantially higher than the corresponding CAC and is independent of the surface energy of the substrates $[7,8]$ on which a droplet of solution spreads out.

Hence, the CWC is a very important parameter, which characterizes the superspreading behaviour of aqueous trisiloxane surfactant solutions and very essential for herbicide delivery and in other deposition applications. With the exception of the idea put forward in $[7,8]$ there are not well elaborated methods for measurements of the CWC for trisiloxanes, while various methods for the measurement of $\mathrm{CAC} / \mathrm{CMC}$ for a wide range of surfactants is available in the literature [9].

In [10] the spreading of droplets of trisiloxane (with 6 and 8 ethoxy groups) solutions over polytetrafluoroethylene (PTFE) copolymer coated silicon wafers was investigated. It was found that at concentrations $C \geq \mathrm{CWC}$ (the $\mathrm{CWC}$ values were taken from [7]), these solutions showed only a partial wetting with the final contact angles of about $50^{\circ}-60^{\circ}$. It was shown in [10] that for both surfactants the dependency of the final contact angle of the spreading droplet on concentration had a sharp change at the concentration close to the CWC value. Hence, the determined CWC values [10] even in the case of partial wetting case coincided with those values obtained for the case of complete wetting [7]. Based on those findings [10] we suggest below a new method of measurement of the CWC values for aqueous trisiloxane surfactant solutions.

The main advantage of the new method is as follows: on silicon wafers coated with amorphous copolymer Teflon AF droplets of surfactants (trisiloxanes and some other nonionic surfactants) reach finite non-zero contact angles which can be easily measured [10] 
as compared with the complete wetting cases [7] where droplets could reach very low barely measurable contact angles. The silicon wafers are molecularly smooth surfaces [11], therefore even coated by Teflon AF copolymer they remain smooth on a molecular scale [12] (see also data in Table 1 below). Hence, there is no roughness, which can affect the final contact angle and the spreading dynamic of droplets.

The objective of the present work is to investigate the dependency of final contact angles on concentration of trisiloxane surfactants with different ethoxy group's length from 4 to 9 , and the commercial Silwet ${ }^{\circledR}$ L-77 surfactant using spreading of aqueous trisiloxane solution droplets over the silicone wafers coated with amorphous copolymer Teflon AF in a wide range of concentrations. The CWCs for all trisiloxanes studied are determined from those measurements.

\section{Experimental section}

\subsection{Materials and methods}

Nonionic ethoxylated trisiloxane surfactants $\left[\left(\mathrm{CH}_{3}\right)_{3} \mathrm{SiO}\right]_{2} \mathrm{Si}\left(\mathrm{CH}_{3}\right)\left(\mathrm{CH}_{2}\right)_{3}\left(\mathrm{OCH}_{2} \mathrm{CH}_{2}\right)_{\mathrm{n}} \mathrm{OH}$, denoted as $T_{n}$, with $n=4,6,8$ and 9 ethoxylate groups were provided by Dr R Hill (Dow Corning Corporation) and used without further purification. Commercially available trisiloxane surfactant (polyalkyleneoxide modified heptanemethyltrisiloxane), Silwet ${ }^{\circledR}$ L-77, with $n=7.5$ ethoxylate groups was purchased from Momentive Performance Materials Gmbh and Co KG, Germany. Poly[4,5-difluoro-2,2-bis(trifluoromethyl)-1,3-dioxole-cotetrafluoroethylene] denoted as PTFE AF (or Teflon AF) was purchased from Sigma-Aldrich, UK. The Fluorinert F75 solvent was purchased from 3M, UK.

Hydrophobic substrates were prepared in the following way. PTFE AF polymer $(0.5 \mathrm{~g})$ was dissolved in $200 \mathrm{~mL}$ of Fluorinert F75 solvent. The silicon wafer pieces measuring approximately $1 \times 1 \mathrm{~cm}$ were carefully cleaned according to the following protocol: $30 \mathrm{~min}$ ultrasonication in isopropyl alcohol, then rinsing in distilled water and soaked in chromic acid 
for 1 hour, intensive rinse in distilled and DI water, and then dried in a strong jet of air. Then silicon wafer pieces were placed in a covered Petri dish and PTFE AF solution was deposited on each piece. After this procedure the silicon wafer pieces were left for 24 hours in order to evaporate the solvent. The macroscopic contact angle of a pure water droplet was found to be $117 \pm 1^{\circ}$ on those substrates (see Table 1 ). The three other polymers such as polystyrene, polypropylene and Parafilm were also used to compare the spreading ability of the trisiloxane solutions. The procedure for the preparation of the polystyrene substrates was similar to those for PTFE AF, that is, polystyrene (1g) was dissolved in $100 \mathrm{ml}$ of dichloromethane solvent and then this solution was deposited onto the silicon wafers which were pre-cleaned according to the above procedure. Polypropylene and Parafilm surfaces were commercially available polymer films. The properties of all polymer surfaces used are summarized in Table 1.

Aqueous trisiloxane surfactant solutions were prepared using ultra pure water (Millipore filter, 18.2 $\mathrm{M} \Omega \mathrm{cm}$ ). The solutions were used within 5 hours of their preparation. Before the experiments the solutions were thoroughly shaken and then ultrasonicated for 10 minutes.

The spreading experiments were conducted under the following conditions: $22 \pm 1^{\circ} \mathrm{C}$ temperature, and at saturated humidity in a closed chamber. A droplet of the surfactant solution of about $3 \mu \mathrm{L}$ was deposited on a PTFE AF coated wafer with a precision syringe. The small size of the droplet allowed the action of gravity to be neglected. The droplets were assumed to have a spherical shape and to spread axisymmetrically, which was confirmed by analysis of droplet images. The side view of the spreading process was captured using a CCD camera at a rate of 30 frames per second. Captured images were analyzed using Drop tracking and evaluation analysis software (Micropore Technologies, UK) to monitor the time evolution of the diameter of the droplet base, height, radius of curvature, contact angle and volume of 
the spreading droplets. For each solution, the experiments were repeated from 5 to 8 times to control the reproducibility. Contact angles were averaged with an error of $1-3^{\circ}$.

For the surface tension measurement experiment all the trisiloxane solutions were made in a phosphate buffer in order to avoid hydrolysis and were prepared just before use. The dynamic surface tension has been measured with a combination of two techniques. A Krüus K10 plate tensiometer with a roughened Pt-plate, and a home-made pendant drop technique with ADSA software were used for measurements in the long-time regime $(t>2 s)$. Measurements were taken every second. The glass cell used in the plate tensiometer was designed in order to minimize evaporation; the stability of the height of the liquid-air interface was checked through the reflectivity of a He-Ne laser beam. In both techniques the temperature was controlled to within \pm 0.02 degrees by circulating water from a Techne thermostat.

Roughness measurements were carried out using an Multimode atomic force microscope (AFM) with a Nanoscope IIIa controller (Veeco, Santa Barbara CA) in the contact mode.

\section{Experimental results and discussion}

\subsection{Parameters affecting spreading}

The contact angle of a liquid droplet on a substrate and the spreading kinetics of the droplet depend on a number of parameters such as the roughness of the substrate, ambient humidity and volume of the droplet. Since the proposed approach relies on the contact angle measuring the influence of those parameters in our case should be taken into consideration.

Topology and roughness of substrates. Some researchers [2, 15] have claimed that the roughness of substrate surfaces does not affect the spreading behaviour, however, there are some papers $[8,16,17]$ which reported on a dependency of the spreading kinetics of surfactant 
solutions [8] as well as the morphology of adsorbed surfactant layers [16] on the roughness of solid substrates and the final contact angle of a droplet [17].

Usually the roughness of substrates is characterized by the root mean square (rms) distribution of the heights of asperities on the surface of interest without paying much attention to the lateral distribution of asperities on the surface. Meanwhile, the peak-to-valley distance could be crucial to the rms value measured on the millimeter scale or even at a hundred microns $[8,11]$. We have measured the roughness of our PTFE AF coated silicon wafers as well as the roughness of polystyrene coated silicon wafers, and Parafilm surfaces using AFM with different scan sizes (Table 1). The rms data for commercially available polypropylene film were taken from the literature [12-14]. Table 1 shows that in the case of the surface of PTFE AF coated silicon wafers the rms is little affected by the increased scan size in comparison with the other three polymers used. The average asperity radius and distance between them were estimated for PTFE AF surfaces using the model proposed by Rabinovich et al [18]. The rms parameter for a $25 \mu \mathrm{m} \times 25 \mu \mathrm{m}$ scanned area was less than $0.93 \mathrm{~nm}$. According to the model [18] the asperity radius is $1.42 \mathrm{~nm}$ whereas the periodicity between asperities is $9 \mathrm{~nm}$. Thus, the surfaces of silicon wafer pieces covered by PTFE AF copolymer can be considered as smooth solids, with the roughness too small to affect the contact angles and spreading dynamics.

Air humidity. It was shown in $[2,19,20]$ that the spreading of trisiloxane surfactant solutions is sensitive to ambient humidity. However, it was reported in [21] that varying the relative humidity between 30 and $80 \%$ does not affect the spreading dynamics significantly. On the other hand, in the case of smooth hydrophobic surfaces a weak influence of humidity on the spreading was reported in [19]. It is obvious that the rate of evaporation of the spreading droplet depends on humidity and hence the contact angle values are in turn affected by humidity because the evaporation mostly occurs at the edge of the droplet [22]. 
In our test experiments on PTFE AF coated silicon wafers it was observed that at relative humidity above $90 \%$ a decrease of the droplet volume due to evaporation was not more than $5 \%$ after a few minutes of spreading. For instance, the spreading of droplet of $\mathrm{T}_{9}$ solution $(C \approx 0.015 \mathrm{mmol} / \mathrm{l})$ with an initial contact angle of $\sim 110^{\circ}$ was completed in $\sim 3$ minutes with a final contact angle of $92^{\circ}$. During that time the droplet lost about $4 \%$ of its volume. After that moment the diameter of the droplet did not change. Over the next 12 minutes a slow evaporation resulted in a volume decrease with a simultaneous $\sim 2^{\circ}$ decrease of the contact angle. At $60-70 \%$ relative humidity the change of droplet volume within approximately 1 minute after deposition of the droplet on the substrate was also insignificant.

In order to decrease an influence of evaporation on the values of contact angles measured the experiments were carried out in a closed chamber at saturated humidity conditions.

Volume of droplets. The final contact angle value is not affected by the volume of a spreading droplet until its radius no longer exceed the capillary length $\left(a=(\gamma / \rho g)^{-1 / 2}\right)$. The capillary length takes on the values of $2.7 \mathrm{~mm}$ for pure water and about $1.5 \mathrm{~mm}$ for trisiloxane solutions at the CAC because of the lower surface tension $(\sim 20 \mathrm{mN} / \mathrm{m})$. At high concentrations (above CWC) the maximum radii of $3 \mu 1$ sessile droplet on PTFE AF substrates were less than $1.5 \mathrm{~mm}$; therefore gravity does not affect the contact angle. In the case of $10 \mu 1$ droplets the values of final contact angles were lower by $2-3^{\circ}$ than those for $3 \mu 1$ droplets. The profile of $10 \mu \mathrm{l}$ droplet (at $C>\mathrm{CWC}$ ) became "pancake" shaped and therefore could not be fitted well by a spherical segment using our software. To avoid these additional errors in the contact angle measurements in our experiments small $(\leq 3 \mu 1)$ droplets were used.

\subsection{Measurement of equilibrium surface tension and CAC}


Fig. 1 shows the equilibrium isotherms for all the trisiloxane surfactants studied. There is no substantial difference between the data obtained using the plate (roughed Pt sensor) and the drop (glass capillary hydrophobized with Teflon) tensiometers. The latter allows us to discard wetting effects on the surface tension measurements. The critical aggregation concentrations, CAC, were calculated from the $\gamma_{\mathrm{eq}}$ versus $\log C$ data by noting the break in the slope and the subsequent plateau in the surface tension. Those results are collected in Table 2 . For $\mathrm{T}_{8}$ at $25^{\circ} \mathrm{C}$ we have obtained $C A C=0.094 \mathrm{mmol} / 1$, that compares favourably with the value $0.09 \mathrm{mmol} / \mathrm{l}$ given by Kumar et al. [23], and also with the values given by Svitova et al. [7] and by Ananthapadnabhan et al. [1] for a commercial trisiloxane $\mathrm{T}_{7.5}$ (Silwet L-77). For the case of $\mathrm{T}_{6}$ our value $(0.06 \mathrm{mmol} / \mathrm{l})$ is smaller than the value of Svitova et al. $(0.096$ mmol/l) [7]. Even though the small number of data points for $\mathrm{T}_{4}$ do not allow a precise estimation of the CAC it seems that the presented data are hardly compatible with the value $0.11 \mathrm{mmol} / 1$ reported by Kumar et al. [23]. The present results indicate that the CAC slightly increases with the length of the polyether chain of the trisiloxane. The increase of CAC with $n$ is expected because of the increase of the hydrophilic tail (ethoxy groups) whilst the hydrophobic head remains the same for all $\mathrm{n}$. The values of the surface tension at the CAC, $\gamma(\mathrm{CAC})$, lies in the range $20-22 \mathrm{mN} / \mathrm{m}$, which is in agreement with the values given in the literature.

\subsection{Measurement of CWC values of trisiloxane solutions}

Fig. 2(a-e) shows the plots of final contact angle of droplets of trisiloxane solutions versus the logarithm of concentration. Fig. 2 clearly shows that for all trisiloxanes $T_{n}(n=4$, $6,7.5,8,9)$ studied the final contact angle gradually decreases with increasing trisiloxane concentration until a plateau is reached. A point of intersection of fitting straight lines for both these parts results in a critical concentration above which no further decrease of the final 
value of the contact angle occurs. Determined in this way concentrations are several times higher than the CACs, therefore although the surface tension of surfactant solutions reached the lowest possible values at the CAC (Fig. 1) the final contact angles continue to decrease with the concentration increase. Hence, as mentioned earlier $[7,8]$ the concentrations determined above (Fig. 2) are really the CWCs (Table 1) above which the complete wetting or superspreading can be expected on moderately hydrophobic substrates [7]. Note that the CWCs presented in Table 1 were extracted from Fig. 2 as an average value between a concentration corresponding to a point of intersection of fitting straight lines and the first experimental point on a plateau.

Note, in case of PTFE AF coated silicone wafers considered above only partial wetting took place and the final contact angles at $C \geq \mathrm{CWC}$ were much higher than zero and can be measured much more reliably. Table 2 shows that the CWCs values for $\mathrm{T}_{6}$ and $\mathrm{T}_{8}$ surfactants determined here are in a good agreement with data previously presented by Svitova et al $[7,8]$ for complete wetting conditions. Moreover, it was shown earlier in [27] that on moderately hydrophobic substrates aqueous solutions of $\mathrm{T}_{6}$ and $\mathrm{T}_{8}$ demonstrate transition to complete wetting at concentration close to the same values of CWCs. In the case of Silwet巴 L-77 surfactant its $\mathrm{CWC}$ was found close to that obtained for $\mathrm{T}_{6}$ surfactant and almost the same as it estimated from the dependency of $\theta_{f}-(C)$ for Silwet ${ }^{\circledR}$ L-77 on Teflon published in [26]. Thus, the independently obtained literature data confirm the validity of our method for measurement of CWC.

The data for $\mathrm{CWC}$ for $\mathrm{T}_{4}$ and both $\mathrm{CAC}$ and $\mathrm{CWC}$ for $\mathrm{T}_{9}$ trisiloxanes are not available in the literature and thus our data cannot be compared with previous results. However the data presented in Table 1 show that the CWC for $\mathrm{T}_{9}$ is close to that for $\mathrm{T}_{8}$ trisiloxane, and the $\mathrm{CWC}$ for $\mathrm{T}_{4}$ surfactant is $2-3$ times smaller than for trisiloxanes with relatively long ethylene 
oxide chains. It correlates with the common tendency for the CWCs values noticed in [7]: the CWC increases as the hydrophobicity of trisiloxanes decrease.

We verify below that CWCs for $\mathrm{T}_{4}, \mathrm{~T}_{9}$, and Silwet ${ }^{\circledR} \mathrm{L}-77$ obtained according to our method corresponds to the previously introduced definition of CWC in the case of moderately hydrophobic surfaces. For that purpose 1-2 $\mu 1$ droplets of solutions of all three trisiloxanes were deposited and spread out over Parafilm and polypropylene films and over polystyrene coated silicone wafers. Characteristics of those substrates such as roughness and wetting properties are summarized in Table 1. Solutions of trisiloxanes were prepared at different concentrations from 1CAC up to 4CWC. Values of CAC and CWC were taken from Table 2. In the case of $\mathrm{T}_{4}$ surfactant the $\mathrm{CAC}$ was taken as an average one between the CAC determined in the present paper and that reported in [23], that is $C A C=0.06 \mathrm{mmol} / \mathrm{l}$.

Fig. 3(a) shows that droplets of $\mathrm{T}_{4}$ solutions showed only partial wetting on all three substrates at all three concentrations $1 \mathrm{CAC}, 1 \mathrm{CWC}$ and $4 \mathrm{CWC}$. Note, that at concentration above the CWC no further change in the final contact angle was observed on all three polymeric substrates, as in the case of the PTFE AF surface (see Fig. 2(a)). Figs. 2(a) and 3(a) prove that the CWC does not depend on the type of substrate that is in accordance with previous results for trisiloxanes $[7,10]$. It means that the critical concentration determined for the $\mathrm{T}_{4}$ trisiloxane using our method is really CWC. However, it does not correspond to the transition to complete wetting for that particular trisiloxane, $\mathrm{T}_{4}$, on moderately hydrophobic substrates. This finding confirms the opinion in the literature that a trisiloxane surfactant with a short hydrophilic group should not be considered as a "superspreader" [28].

Figs. 3(b-c) present the dependency of the final contact angles of droplets of $\mathrm{T}_{9}$ and Silwet L-77 solutions on concentrations on Parafilm, polypropylene and polystyrene surfaces. Figs. 3(b-c) confirm that the behaviour of these dependencies abruptly changes at the concentrations identified as CWC according to Fig. 2 and summarized in Table 2. At 
$C \geq \mathrm{CWC}$ the droplets of solutions of both trisiloxanes completely spread out over polypropylene and polystyrene surfaces for the time span varying from ten seconds to one minute. For instance, on the polypropylene surface $1 \mu$ droplets of $\mathrm{T}_{9}$ at $C \approx 4 \mathrm{CWC}$ reached the pancake shape over $\sim 2 \mathrm{~s}$ and then spread as thin layers whose contact angles could not be measured due to their small size. On the more hydrophobic and rough Parafilm the only partial wetting occurs for both $\mathrm{T}_{9}$ and Silwet L-77 surfactants even at $\mathrm{C}>\mathrm{CWC}$, but the spreading ability of Silwet L-77 on Parafilm was much higher than that for $\mathrm{T}_{9}$ (see Figs. 3bc). Note that the final contact angles of Silwet L-77 droplets at $C \geq \mathrm{CWC}$ on Parafilm and $\mathrm{T}_{9}$ droplets at $\mathrm{C} \approx \mathrm{CWC}$ on polystyrene surface still differ from zero, but their values are quite low and lie in the range of accuracy of the measurement. Those droplets form relatively thick (tens of microns) pancakes with still detectable contact angles. Although this case of wetting is still a partial wetting, it could be characterized as so-called "frustrated-complete wetting state", which corresponds to a very small spreading coefficient $\sim 10^{-6} \mathrm{~N} / \mathrm{m}[29]$.

The latter facts clearly demonstrate the advantage of PTFE AF coated silicon wafers for precise measurement of the contact angles of spreading droplets when the CWC needs to be determined as compared with the others widely used polymers.

\section{Conclusions}

The CWC was firstly determined in the literature as a concentration above which the transition from partial wetting to complete wetting occurs on moderately hydrophobic surfaces. However, there are hydrophobic surfaces with higher hydrophobicity which cannot be wetted completely even by superspreaders. We suggested a new approach to estimate CWCs relying on a partially wetting behaviour of trisiloxane solutions on highly hydrophobic smooth Teflon AF coated silicon wafers. On those substrates the droplets of aqueous trisiloxane surfactants reached the constant final contact angle and no further decrease of the final contact angle occurs at the concentration, identified as the CWC. The advantages of the 
new procedure are the following: in the case of partial wetting the final contact angles can be easily and precisely measured as compared with the complete wetting cases; because silicon wafers are highly smooth materials roughness does not affect the final contact angle, the spreading dynamic of droplets and, hence, measured values of CWCs.

According to the new approach the CWCs for trisiloxane surfactants $T_{n}$ with different numbers of ethylene oxide units, $\mathrm{n}=4,6,7.5,8,9$, have been measured. It has been shown that for all trisiloxanes studied the CWCs are several times (in some cases one order of magnitude) higher than their corresponding CAC values. The value of CWC increases with increasing length of the hydrophilic tail. Experiments on spreading droplets of aqueous solutions of all trisiloxanes studied over polystyrene and polypropylene surfaces have verified that the CWCs obtained according to our approach are in a good agreement with the previously measured CWCs for the case of moderately hydrophobic surfaces and complete wetting. It has also been found that the CWC value for each individual trisiloxane does not depend on hydrophobicity of substrates.

\section{Acknowledgment}

This research was supported by Engineering and Physical Sciences Research Council, UK (Grant EP/D077869/1) and by EU under Grant MULTIFLOW, FP7-ITN- 2008-214919. 


\section{Figure legends}

Fig. 1. Surface tension isotherms at $25^{\circ} \mathrm{C}$ for all trisiloxanes studied.

Fig. 2. Dependencies of the final contact angles on concentration for droplets of trisiloxanes surfactant solutions on PTFE AF coated silicon wafers: (a) - $\mathrm{T}_{4},(\mathrm{~b})-\mathrm{T}_{6}$, (c) - Silwet ${ }^{\circledR} \mathrm{L}-77$, (d) $-\mathrm{T}_{8}$, and (e) $-\mathrm{T}_{9}$.

Fig. 3. The cosine of the final contact angle versus concentration of trisiloxanes, $\mathrm{T}_{4}-(\mathrm{a}), \mathrm{T}_{9}-$ (b), Silwet L-77 - (c), on different polymer surfaces: - - Parafilm (PF), - polystyrene (PS), - - polypropylene (PP). 


\section{References}

1. Ananthapadmanabhan K.P., Goddard E.D., Chandar P. Colloids and Surfaces. 1990. 44, 281-297.

2. Zhu S., Miller W.G., Striven L.E., Davis H.T. Colloids and Surfaces A: Physchem. and Eng. Aspects. 1994. 90, 63-78.

3. He M., Hill R.M., Lin Z., Scriven L.E., Davis H.T. J. Phys. Chem., 1993. 97(34), 88208834.

4. Hill R.M., He M., Davis H.T., Scriven L.E. Langmuir. 1994. 10, 1724 - 1734.

5. Li X., Washenberger R.M., Scriven L.E., Davis H.T., Hill R.M. Langmuir. 1999. 15, 22782289.

6. Schwarz E.G. Reid W.G. Ind. Eng. Chem. 1964. 56(9), 26-31.

7. Svitova T., Hill R.M., Smirnova Yu., Stuermer A., Yakubov G. Langmuir. 1998. 14, 50235031.

8. Svitova T., Hill R.M., Radke C.J. Colloids and Surfaces A: Physchem and Eng. Aspects. 2001. 183-185, 607-620.

9. Harris J.C. JAOCS. 1958. 35(11), 611-674.

10. Ivanova N., Starov V., Johnson D., Hilal N., Rubio R. Langmuir. 2009. 25(6), 3564-3570.

11. Malik I.J., Pirooz S., Shive L.W., Davenport A.J., Vitus C.M. J. Electrochem. Soc. 1993. 140(5), L75-L77.

12. Dutschk V, Sabbatovskiy K.G, Stolz M, Grundke K, Rudoy V.M. J. Colloid Interfaces Sci, 2003. 267, 456-462.

13. Leroux F., Campagne Ch., Perwuelz A., Gengembre L. J. Colloid Interfaces Sci. 2008. $328,412-420$.

14. Frank J., Simon F., Schmidt F.-J. Phys. Chem. Chem. Phys. 1999. 1, 3865-3869. 
15. von Bahr M., Tiberg F., Yaminsky V. Colloids and Surfaces A: Physicochemical and Engineering Aspects. 2001. 193, 85-96.

16. Schniepp H.C., Shum H.C., Saville D.A., Aksay I.A. J. Phys. Chem. B. 2007. 111(30), 8708-8712.

17. Adamson A.W., Gast A.P. Physical Chemistry of Surfaces. $6^{\text {th }}$ Ed. New York: WileyInterscience; 1997.

18. Rabinovich Y.I., Adler J.J, Ali Ata, Singh R.K., Moudgil B.M. J. Colloid Interfaces Sci. 2000. 232, 10-16.

19. Lin Z., Hill R.M., Davis T., Ward M.D. Langmuir. 1994. 10, 4060-4068.

20. Venzmer J., Wilkowski S.P. Trisiloxane surfactants - mechanisms of spreading and wetting. Pesticide Formulation and application Systems: $18^{\text {th }}$ Volume, ASTM STP 1347, J.D. Nalewaja, G.R. Goss, and R.S. Tann, Eds., American Society for Testing and Materials, 1998, $140-151$.

21. Rafai S., Sarker D., Bergeron V., Meunier J., Bonn D. Langmuir. 2002.18 (26), 1048610488.

22. Starov V., Sefiani K. Colloids and Surfaces A: Physchem. and Eng. Aspects. 2008. doi:10.1016/j.colsurfa.2008.09.047.

23. Kumar N., Couzis A., Maldarelli C. J. Colloid Interfaces Sci. 2003. 267, 272 -285.

24. Xiaolan Tang, Jinfeng Dong, Xuefeng Li. J. Colloid Interfaces Sci. 2008. 325, 223-227. 25. Wagner R, Richter L, Weißmuller J., Reiners J., Klein K.D., Schaefer D. Stadtmuller S. Appl. Organometal. Chem. 1997. 11, 617-632.

26. Radulovic J., Sefiane K., Shanahan M.E.R. J. Colloid Interfaces Sci. 2009. 332, 497-504.

27. Caleb Chong Wei Ping, Ivanova N.A., Starov V.M., Hilal N, Johnson D. Colloid Journal. 2009. 71(3), 1-6.

28. Ruckenstein E. J. Colloid Interfaces Sci. 1996. 179, 136-142. 
29. Bonn D., Eggers J., Indekeu J., Meunier J., Rolley E. Wetting and spreading. Rev. Mod. Phys. 2009. 81(2), 739-805. 
Table 1. Physical characteristics of polymer films and silicon wafers coated with polymers.

\begin{tabular}{|c|c|c|c|c|}
\hline \multirow{3}{*}{$\begin{array}{c}\text { Scanned area, } \\
\mu \mathrm{m} \times \mu \mathrm{m}\end{array}$} & \multicolumn{4}{|c|}{ The roughness of polymer surfaces, RMS, nm } \\
\hline & \multicolumn{2}{|c|}{ Silicon wafers coated by polymers } & \multirow{2}{*}{ Parafilm ${ }^{\circledR} \mathrm{M}$} & \multirow{2}{*}{ Polypropylene } \\
\hline & PTFE AF & Polystyrene & & \\
\hline $5 / 4$ & $0.51 /$ & $/ 0.755$ & $7.74 /$ & $/ 5.8 \pm 2.6[13]$ \\
\hline $20 / 25$ & $/ 0.93$ & $/ 1.29$ & $35.85 /$ & $<2[12]$ \\
\hline 50 & 2.84 & 2.46 & 63.91 & - \\
\hline 100 & 4.15 & 5.47 & 104.90 & $51 \pm 15[14]$ \\
\hline $\begin{array}{l}\text { Contact angle } \\
\text { of pure water, } \\
\text { (degree) }\end{array}$ & $117 \pm 1$ & $89 \pm 3$ & $106 \pm 2$ & $97 \pm 1$ \\
\hline
\end{tabular}

Table 2. Critical aggregation concentration and critical wetting concentration of the trisiloxane solutions at $25^{\circ} \mathrm{C}$. The estimated uncertainty in the CAC is $\pm 0.003 \mathrm{mmol} / \mathrm{l}$.

\begin{tabular}{cccccc}
\hline Surfactant & $\begin{array}{c}\mathrm{CAC}, \\
\mathrm{mmol} / \mathrm{l}\end{array}$ & $\begin{array}{c}\mathrm{CAC}^{a}, \\
\mathrm{mmol} / 1\end{array}$ & $\begin{array}{c}\mathrm{CWC}, \\
\mathrm{mmol} / 1\end{array}$ & $\begin{array}{c}\mathrm{CWC}^{a}, \\
\mathrm{mmol} / \mathrm{l}\end{array}$ & $\begin{array}{c}\text { Molecular } \\
\text { weight }\end{array}$ \\
\hline $\mathrm{T}_{4}$ & 0.022 & $0.11[23]$ & $0.312 \pm 0.050$ & - & 456 \\
$\mathrm{~T}_{6}$ & 0.061 & $0.096[7]$ & $0.527 \pm 0.030$ & $0.552[7]$ & 544 \\
Silwet® L-77 & 0.07 for & $\begin{array}{c}0.11[1] \\
0.13[24]\end{array}$ & $0.40 \pm 0.01$ & $0.410[26]$ & 610 \\
& $\mathrm{~T}_{7}$ & $0.17[25]$ & & & \\
$\mathrm{T}_{8}$ & 0.094 & $0.101[7]$ & $0.698 \pm 0.080$ & $0.79[7]$ & 632 \\
& & $0.091[23]$ & & & 676 \\
\hline
\end{tabular}

$\bar{a}-$ data collected from literature. 


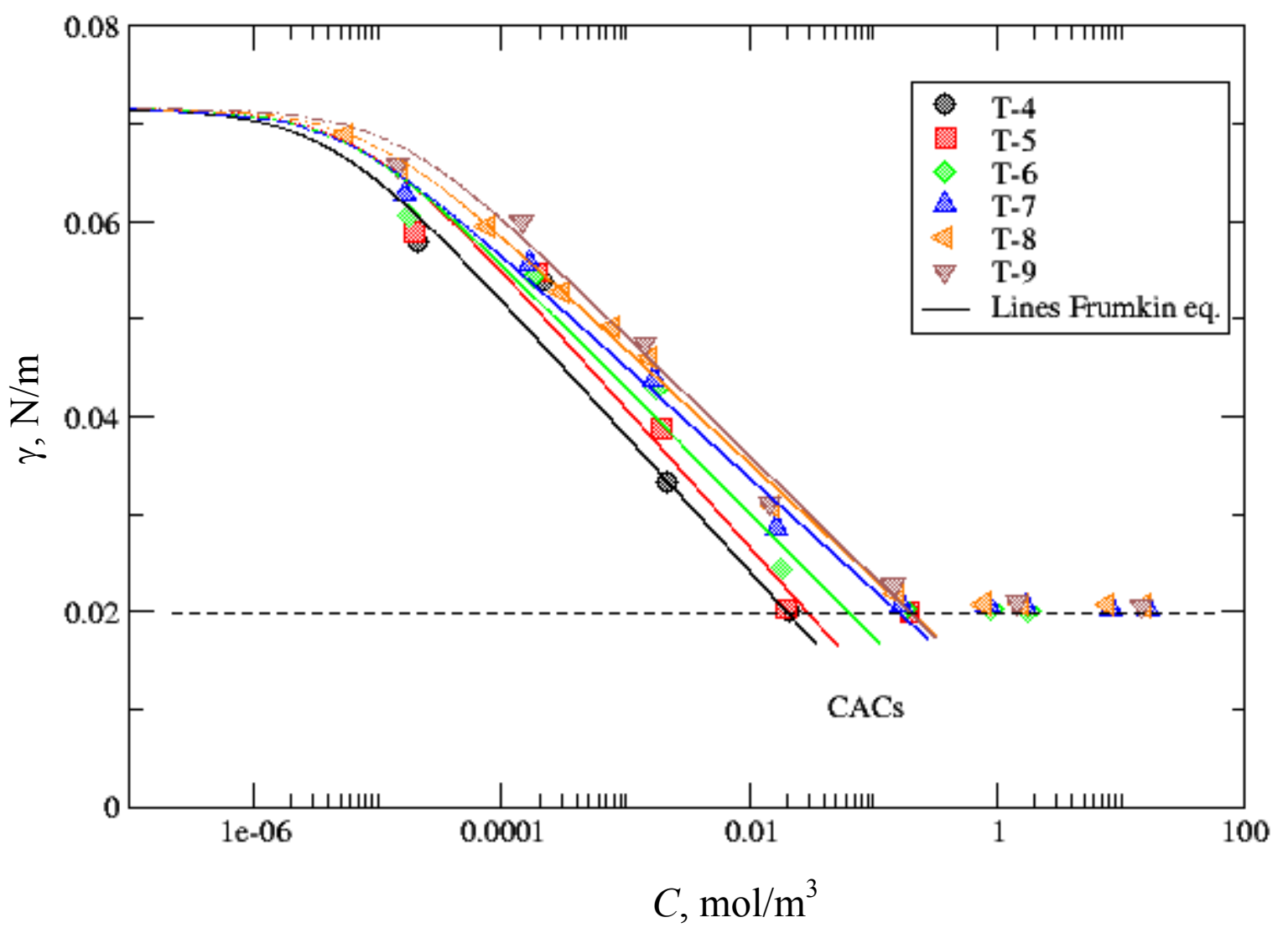

Fig. 1. Surface tension isotherms at $25^{\circ} \mathrm{C}$ for all trisiloxanes studied. 

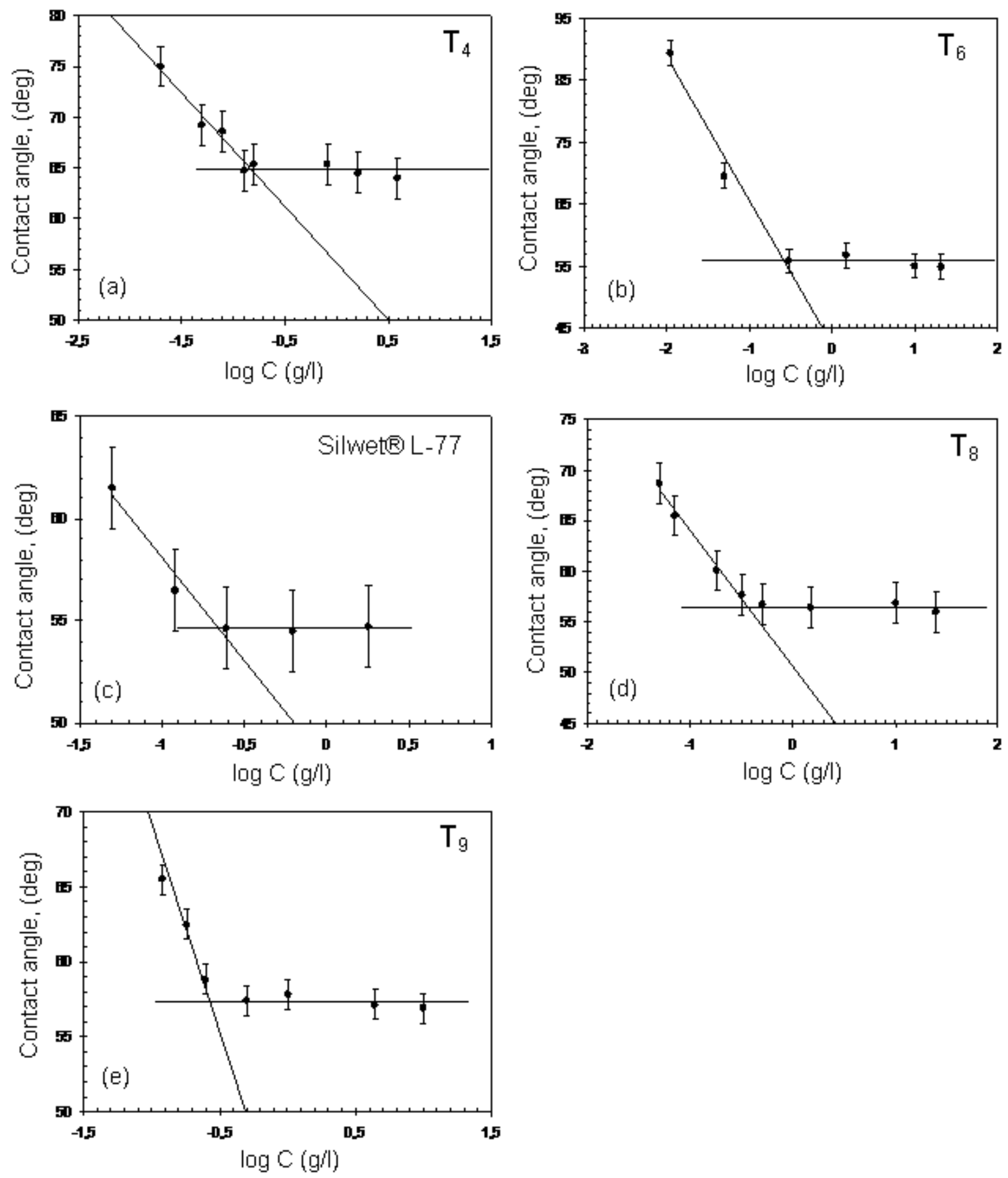

Fig. 2. Dependencies of the final contact angles on concentration for droplets of trisiloxanes surfactant solutions on PTFE AF coated silicon wafers: (a) - $\mathrm{T}_{4}$, (b) - $\mathrm{T}_{6}$, (c) - Silwet ${ }^{\circledR} \mathrm{L}-77$, (d) $-\mathrm{T}_{8}$, and (e) $-\mathrm{T}_{9}$. 

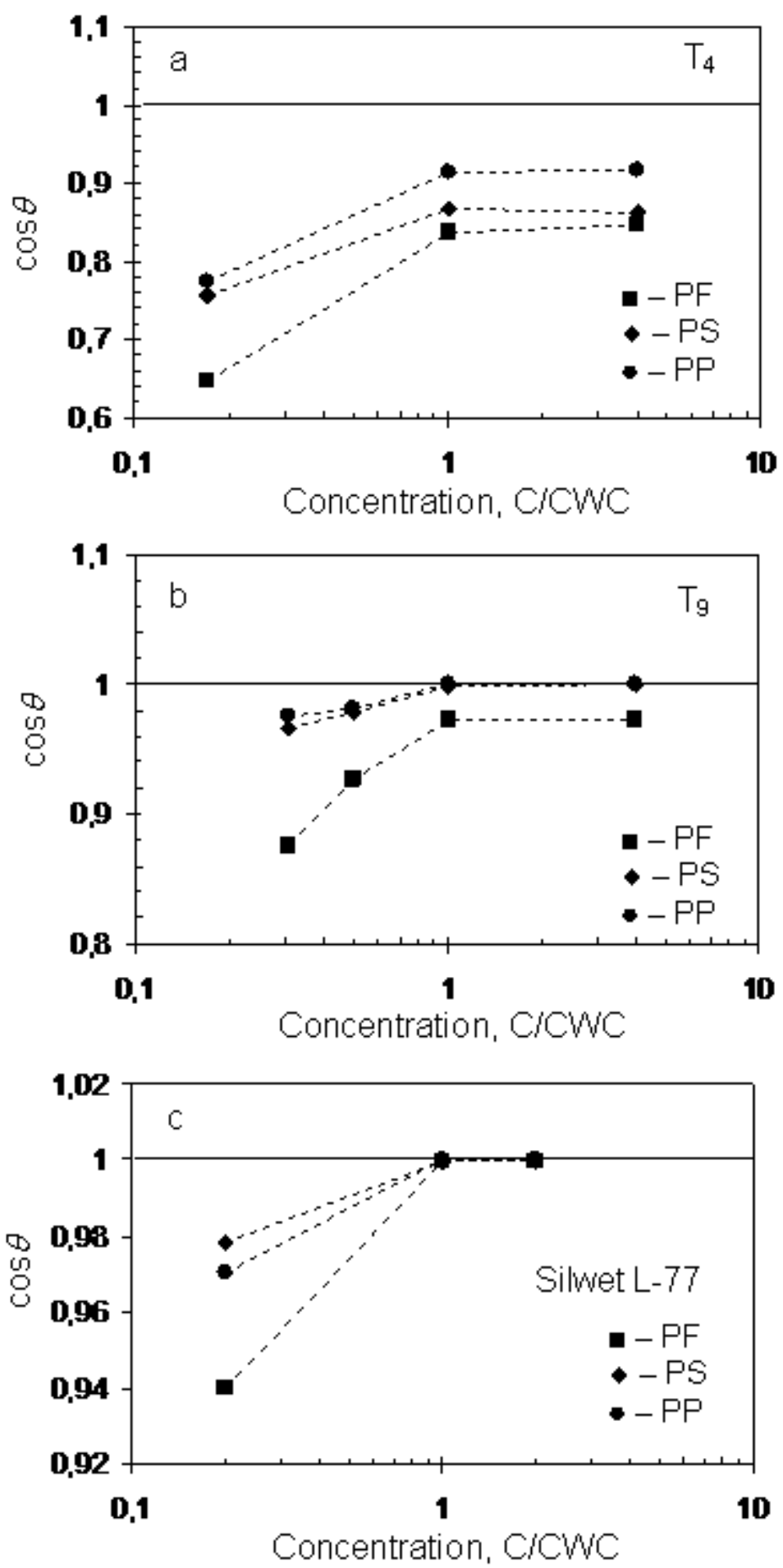

Fig. 3. The cosine of the final contact angle versus concentration of trisiloxanes, $\mathrm{T}_{4}-(\mathrm{a}), \mathrm{T}_{9}-$ (b), Silwet L-77 - (c), on different polymer surfaces: - - Parafilm (PF), - polystyrene (PS), - - polypropylene (PP). 